\title{
Influence of landscape characteristics on carnivore diversity and abundance in Mediterranean farmland
}

\author{
Ricardo Pita ${ }^{\mathrm{a}, \mathrm{b}, *}$, António Mira ${ }^{\mathrm{a}, \mathrm{b}}$, Francisco Moreira ${ }^{\mathrm{c}}$, Rui Morgado ${ }^{\mathrm{c}}$, Pedro Beja ${ }^{\mathrm{d}, \mathrm{e}}$ \\ a Unidade de Biologia da Conservação, Universidade de Évora - Núcleo da Mitra, Apartado 94, 7002-554 Évora, Portugal

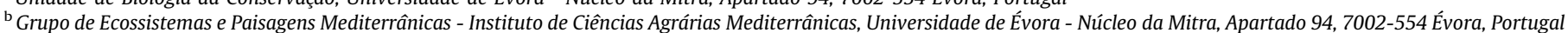 \\ 'Centro de Ecologia Aplicada "Prof. Baeta Neves", Instituto Superior de Agronomia, Universidade Técnica de Lisboa, Tapada da Ajuda, 1349-017 Lisboa, Portugal \\ 'ERENA, Ordenamento e Gestão de Recursos Naturais Lda, Rua Robalo Gouveia, 1-1A, 1900-392 Lisboa, Portugal \\ ${ }^{\text {e } C I B I O ~-~ C e n t r o ~ d e ~ I n v e s t i g a c ̧ a ̃ o ~ e m ~ B i o d i v e r s i d a d e ~ e ~ R e c u r s o s ~ G e n e ́ t i c o s, ~ U n i v e r s i d a d e ~ d o ~ P o r t o, ~ C a m p u s ~ A g r a ́ r i o ~ d e ~ V a i r a ̃ o, ~ 4485-66 ~ V a i r a ̃ o, ~ P o r t u g a l ~}$
}

\section{A R T I C L E I N F O}

\section{Article history:}

Received 28 October 2008

Received in revised form 25 February 2009

Accepted 27 February 2009

Available online 28 March 2009

\section{Keywords:}

Agricultural intensification

Arable habitats

Conservation

Land abandonment

Irrigation

Multimodel inference

Predation risk

\begin{abstract}
A B S T R A C T
Predation is increasingly pointed out as one of the factors contributing to population declines of groundnesting farmland birds, though it remains poorly understood how ongoing transformations of agricultural landscapes affect predator assemblages. This study addressed this issue, estimating the contribution of landscape composition and configuration to spatial variation in species richness and abundances of mammalian carnivores across a gradient of agricultural intensification in southern Portugal. The carnivore assemblage was diverse (10 species), but it was largely dominated by just three widespread and abundant species of generalist predators: domestic dog (Canis familiaris), red fox (Vulpes vulpes) and Egyptian mongoose (Herpestes ichneumon). The number of domestic carnivore species and the abundance of cats (Felis catus) increased along with farmland occupation by human dwellings, whereas dogs were not responsive to landscape variables. The species richness of wild carnivores was highest in landscapes with a patchwork of arable fields and semi-natural habitats such as forests and shrubland, though it was also high in irrigated landscapes with dense networks of irrigation channels and tree lines bordering agricultural fields. Irrigation was also positively associated with the abundance of otters (Lutra lutra) and mongooses. Cats, foxes, badgers (Meles meles), and total and wild carnivore abundances, were positively affected by increasing cover by eucalyptus and pine forest plantations. In general, results suggest that the highest diversity and abundance of carnivores in Mediterranean farmland may occur in mosaic landscapes with small agricultural fields, high cover by woody vegetation patches and corridors, and many human dwellings. Preventing scrub encroachment and afforestation may thus be necessary to maintain a low predation risk in open farmland habitats, which are often inhabited by ground-nesting birds of high conservation concern. Conversely, keeping shrubland and forest patches within farmed landscapes may be essential where carnivore persistence is a relevant conservation goal.
\end{abstract}

(c) 2009 Elsevier B.V. All rights reserved.

\section{Introduction}

Over the past decades, European agricultural landscapes have gone through a process of significant transformations associated with a period of intense and rapid economic and social changes (Vos and Meekes, 1999; Stoate et al., 2001; Jongman, 2002; Aranzabal et al., 2008). Across most of Europe, there has been a pervasive trend for land-use intensification and the loss of seminatural habitats in the most productive regions, along with scrub encroachment and afforestation in marginal farming areas (Falcucci et al., 2007; Van Doorn and Bakker, 2007; Aranzabal

\footnotetext{
* Corresponding author. Tel.: +351 917802087; fax: +351 217991119.

E-mail address: ricardo.pita@gmail.com (R. Pita).
}

et al., 2008). These transformations have resulted in major population declines of farmland species over vast geographic areas and across taxonomic groups, prompting a quest for the agricultural practices most favourable to the conservation of biodiversity within farmed landscapes (e.g., Benton et al., 2003; Aschwanden et al., 2007; Henle et al., 2008; Maes et al., 2008; Wade et al., 2008).

Agri-environmental management prescriptions are often targeted at maintaining or restoring critical feeding, reproduction or dispersal habitats of species or assemblages or species, generally assuming a direct link between habitat loss and farmland population declines (Stoate et al., 2001; Beja and Alcazar, 2003; Aschwanden et al., 2007; Henle et al., 2008; Maes et al., 2008; Wade et al., 2008). However, other indirect links may affect populations in changing farmland landscapes. For instance, the 
increasing abundance of invasive and commensal species has very often unknown consequences for the survival of indigenous species, as a result of the potential changes in competition and predation interactions (Shapira et al., 2008). This suggests that altered biotic interactions, particularly predation processes, could rival habitat change as a causal agent in farmland population declines (e.g., Evans, 2004). Different studies have indeed emphasised the relationships between landscape transformations and potential predation effects on farmland biodiversity, involving both the direct killing of individuals and changes in their behaviour and habitat selection patterns to reduce predation risk (Whittingham and Evans, 2004; Eggers et al., 2005; Wallander et al., 2006; Sims et al., 2008). Nevertheless, information on how agricultural change affects predator abundance and predation patterns and, hence, the persistence of many farmland species, is still scarce. Research on this subject is thus needed in order to improve agrienvironmental schemes designed to retain farmland biodiversity, particularly in highly managed landscapes.

In Mediterranean Europe, predation has been increasingly invoked to explain patterns of habitat selection and dynamics of declining populations of open farmland birds (Silva et al., 2004; Moreira et al., 2005; Reino et al., 2009), as well as that of other species of conservation importance such as for instance the European rabbit Oryctolagus cuniculus (Calvete et al., 2004) and the Cabrera vole Microtus cabrerae (Pita et al., 2007). Although limited information is generally available to support these contentions, there is already some evidence indicating that ground-nesting passerines are highly vulnerable to predation in farmland landscapes (Yanes and Suárez, 1995), that changes in predation rates may vary with agricultural land uses (Pescador and Peris, 2001), and that population declines may occur due to increased densities of generalist predators such as foxes (Vulpes vulpes) and feral dogs (Canis familiaris) (Suárez et al., 1993; Yanes and Suárez, 1996). It remains unresolved, however, whether current trends of agricultural change affect the interactions between predators and protected species, partly due to a poor understanding on the composition and structure of predator assemblages inhabiting Mediterranean farmland, and how these are affected by landscape change (but see Falcucci et al., 2007). For instance, it remains poorly understood how predators respond to changes in agricultural field size or in the amount and spatial configuration of interstitial habitats such as hedges or woodlots, which often vary along with changes in agricultural land uses (e.g., Jongman, 2002). This information is particularly needed in the case of mammalian carnivores, which may be among the most influential predators in farmed landscapes and for which this kind of information is largely lacking (but see Virgós et al., 2002; Mangas et al., 2008). Furthermore, some of the carnivores likely to occur in Mediterranean farmed landscapes are also considered of conservation concern (e.g., Lozano et al., 2003; Mestre et al., 2007), which may generate dilemmas between the conservation of predators and that of their prey.

This study addressed these issues by examining correlates of carnivore assemblage variation across a Mediterranean farmland landscape, in a region where extensive agricultural land uses have been progressively abandoned or replaced by intensive irrigated agriculture, with overall negative consequences for farmland biodiversity (Beja and Alcazar, 2003; Pita et al., 2007). Specifically, the study quantified relationships between landscape patterns and carnivore assemblage attributes, in terms of species richness and abundance of the most widespread species. The study focused on variables reflecting landscape composition and structure, because these have been shown to strongly affect carnivore assemblages (Gehring and Swihart, 2003; Virgós et al., 2002; Mangas et al., 2008). Results were then used to discuss how landscape changes may affect the persistence of Mediterranean farmland carnivores, and how these in turn may affect populations of declining farmland species, particularly ground-nesting birds.

\section{Methods}

\subsection{Study area}

The study was conducted in the coastal plateau of southwestern Portugal. The region is included in the thermo-Mediterranean bioclimatic zone (Rivas-Martinez, 1981), with mean temperatures of about $16{ }^{\circ} \mathrm{C}$ and mean annual rainfall around $650 \mathrm{~mm}$, of which $>80 \%$ falls in October to March. This arable landscape is mainly devoted to irrigated agriculture and livestock production. Woody cover within the agricultural landscape is restricted to some woodlots and hedges delimiting fields and protecting crops from maritime winds. Shrubby hedges are most frequent around small fields close to villages, whereas tree lines were planted around larger fields generally devoted to irrigated agriculture. There are also more natural areas surrounding and interspersing the arable landscape, including coastal dunes, open cork oak (Quercus suber) woodlands, and Mediterranean woodlands and shrublands covering the slopes of entrenched rivers and streams crossing the coastal plateau. Although the area is included in a Natural Park and within a Site of Community Importance classified under the European Directive 92/43/CEE, agriculture is becoming ever more intensive since the early 1990s. Intensification processes include: (i) increases in cattle stock densities and the replacement of extensive pastureland by improved pastures; (ii) increases in the area occupied by vegetable crops for international markets, often grown in greenhouses; (iii) the loss of semi-natural habitats such as temporary ponds and shrubland; (iv) increases in the size of irrigated fields, which are mainly used for fodder crops such as corn and sorghum; and (v) the development of paved road networks (Beja and Alcazar, 2003; Pita et al., 2007). These changes have shown measurable negative impacts on amphibians (Beja and Alcazar, 2003), birds (Alcazar, 2003), and small mammals (Pita et al., 2007). Despite the overall trend for agricultural intensification, some areas have been abandoned or maintain extensive agricultural land uses, due for instance to the lack of irrigation infrastructures or legal constraints.

\subsection{Carnivore surveys}

This study is part of a larger research program investigating predation patterns and processes in Mediterranean farmland, involving 60 agricultural fields selected randomly along the coastal plateau of southwestern Portugal, 17 of which were sampled in 2002 and another 43 in 2003. Carnivores were surveyed on three occasions (spring, summer and autumn) between March and October, within circular $1-\mathrm{km}$ radius plots $\left(3.14 \mathrm{~km}^{2}\right)$ centred on each field (Fig. 1). This spatial extent was considered adequate for surveying carnivores at large spatial scales in the southern Iberian Peninsula (e.g., Barea-Azcón et al., 2006), and it was also expected to reflect the wide range of landscape types across the study area.

Carnivore surveys were based on the detection of indirect field signs of their presence, including both faeces and footprints (e.g., Matos et al., 2009; Beja et al., in press). Faeces of the different species were identified according to shape, size, odour and location, discarding scats showing ambiguous identity to reduce identification errors (Barea-Azcón et al., 2006; Mangas et al., 2008). Footprints were also used because they can generally be identified with more certainty than faeces, though they are also prone to potential errors as their presence or absence may be strongly influenced by substrate type (Barea-Azcón et al., 2006). This potential problem was not considered important in the present study area, because the soil was generally sandy and there were 


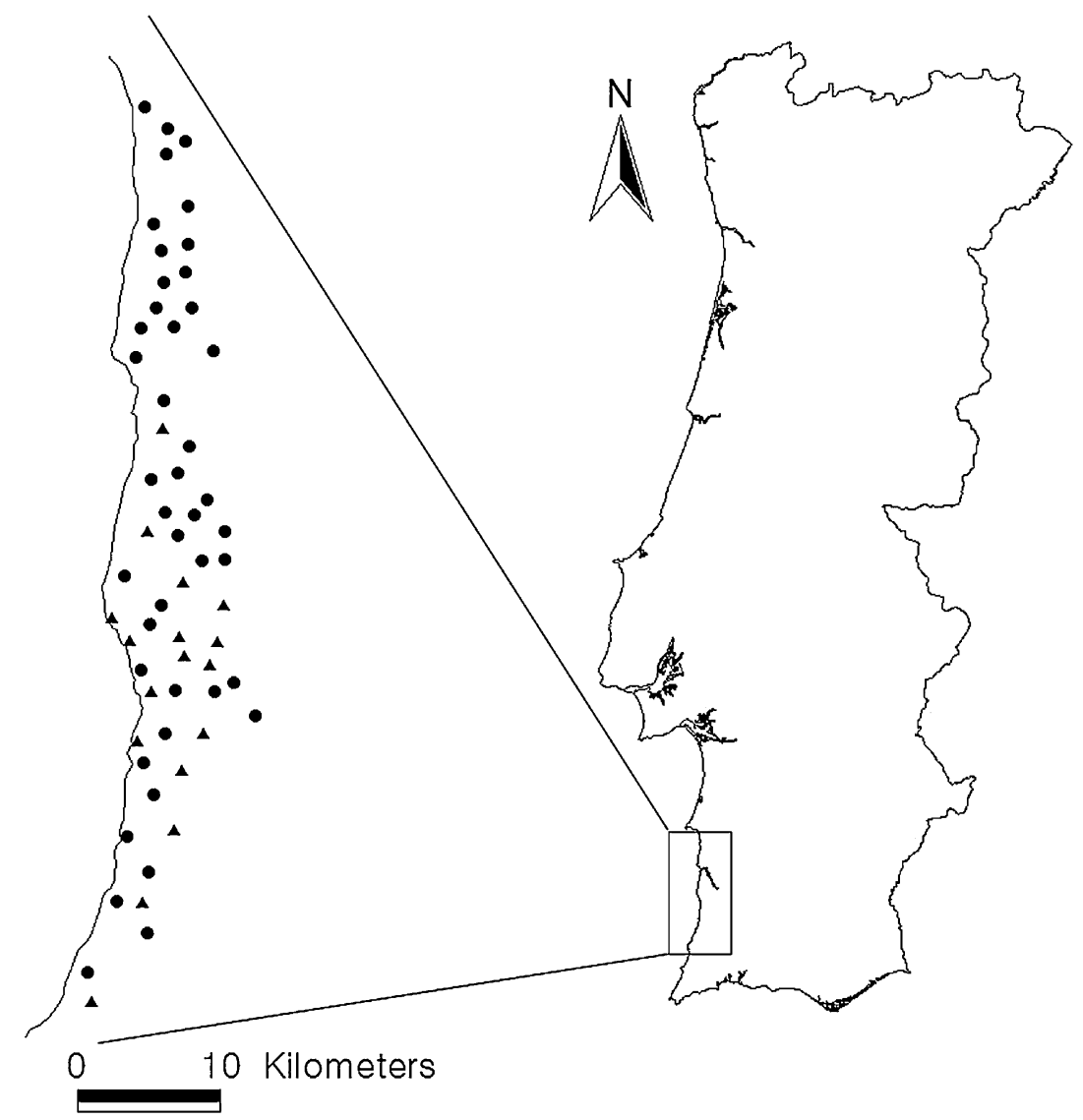

Fig. 1. Location of the 60 plots sampled for carnivores in 2002 (triangles) and 2003 (circles), along the coastal plateau of southwestern Portugal.

many places with bare ground where carnivore tracks were easy to record and identify. Although surveys based on field signs have been the subject of some criticism (e.g., Walker et al., 2000), this approach is generally considered valid for studies conducted at the landscape or regional scales (Virgós, 2001; Wilson and Delahay, 2001; Beja et al., in press), based on strong evidence indicating a good fit between carnivore field signs and population density or animals activity (e.g., Tuyttens et al., 2001; Sadlier et al., 2004; Barea-Azcón et al., 2006). This method represents a reasonable alternative to trapping or scent-station methods, as these are too expensive, time-consuming and generally rely on attractants to detect the assemblage of species in a given area (Sadlier et al., 2004; Virgós and Travaini, 2005; Barea-Azcón et al., 2006). Sampling each plot on three different occasions also contributed to reduce problems normally associated with sign surveys, by encompassing eventual variability in the activity of different species over the year. All plots were surveyed over a short time interval on each sampling season, to minimise differences in sign decay rates among plots due to changing weather conditions.

On each sampling plot, carnivores were surveyed along permanent linear transects, thoroughly searching for the presence of indirect field signs within a 20-m wide strip to each side of the main path (Beja et al., in press). The relative abundance of each species on each plot and sampling season was then estimated from the total number of signs recorded per kilometre of transect. To enhance comparability among plots sampled across the study area, transects were always surveyed by the same observer (RP) and the total length of transects was similar across plots, averaging $2212.0 \mathrm{~m} \pm 31.2$ (standard error). Transects were placed so that dominant land uses were sampled approximately in proportion to their availability, and they generally followed dirt tracks, fences, field edges, ditches, and riverbanks. The association of transects with linear structures was unavoidable due to constraints of access within the farmed landscape, but it is recognised that it may overestimate the relative abundances of species such as foxes that are attracted by these landscape features (Virgós, 2001). This problem was minimised by searching a relatively wide stripe to each side of the main path, thereby encompassing a wider range of habitat types. Furthermore, consistency of sampling conditions across the study area makes it unlikely that variation in carnivore species richness and abundance patterns among plots was greatly affected by this potential sampling bias.

\subsection{Landscape variables}

Factors influencing carnivore abundances were estimated considering three sets of explanatory variables describing landscape composition, configuration and the density of linear structures (Table 1 ). These variables were selected because they likely reflect changes in agricultural land uses across the study area, and they are known to affect carnivore habitat use and movement patterns (e.g., Gehring and Swihart, 2003; Virgós et al., 2002; Rands and Yunger, 2006; Mangas et al., 2008). Landscape composition was estimated from the proportion of area occupied by arable land, social areas, tree plantations and semi-natural habitats (see Table 1 for class description), quantified in a Geographic Information System from land cover maps. Maps were based on the photointerpretation of digital orthophotos from 2002 (1:22,000), validated through systematic field checking of the sampling plots carried out in 2003. Landscape configuration was estimated from the mean size, edge density and the area weighed mean shape index (AWMSI) of arable patches, considering a minimum mapping unit of 0.5 ha. AWMSI is a measure of shape complexity, which is the average perimeter-to-area ratio for a 
Table 1

Description and summary statistics of variables used to examine carnivore responses to landscape composition and configuration in southern Portugal.

\begin{tabular}{|c|c|c|c|c|}
\hline Variable (unit) & Description & Transformation & Mean \pm S.E. & Range \\
\hline \multicolumn{5}{|l|}{ Landscape composition } \\
\hline Agricultural land cover (\%) & Proportion of area with arable fields and pastureland & Angular & $65.8 \pm 2.3$ & $31.2-93.4$ \\
\hline Social areas cover $(\%)$ & Proportion of area with urban areas, isolated farmhouses and infrastructures & Angular & $2.1 \pm 0.3$ & $0.0-9.6$ \\
\hline Tree plantations cover (\%) & Proportion of area with pine and eucalyptus plantations & Angular & $15.4 \pm 1.23$ & $0.6-42.3$ \\
\hline Semi-natural habitats cover (\%) & Proportion of area with cork oak woodlands, shrubland, marshes and coastal dunes & Angular & $15.4 \pm 1.9$ & $0.1-65.3$ \\
\hline \multicolumn{5}{|l|}{ Landscape configuration } \\
\hline MPS (ha) & Mean size of agricultural patches & Logarithmic & $54.8 \pm 8.2$ & $9.8-292.0$ \\
\hline $\mathrm{ED}\left(\mathrm{km} / \mathrm{km}^{2}\right)$ & Density of edges between agricultural land and other land cover classes & Logarithmic & $8.2 \pm 0.3$ & $4.2-15.6$ \\
\hline AWMFD & Area weighed mean fractal dimension of agricultural patches & - & $1.4 \pm 0.01$ & $1.3-1.4$ \\
\hline \multicolumn{5}{|l|}{ Linear structures } \\
\hline Irrigation channels $\left(\mathrm{km} / \mathrm{km}^{2}\right)$ & Density of irrigation channels & Logarithmic & $0.6 \pm 0.1$ & $0.0-2.6$ \\
\hline Road network $\left(\mathrm{km} / \mathrm{km}^{2}\right)$ & Density of paved and dirt roads & Logarithmic & $3.7 \pm 0.1$ & $1.4-6.4$ \\
\hline Tree lines $\left(\mathrm{km} / \mathrm{km}^{2}\right)$ & Density of linear strips with planted trees & Logarithmic & $1.2 \pm 0.1$ & $0.1-2.8$ \\
\hline Shrubby hedges $\left(\mathrm{km} / \mathrm{km}^{2}\right)$ & Density of shrubby linear strips & Logarithmic & $1.0 \pm 0.1$ & $0.1-4.5$ \\
\hline
\end{tabular}

given class, weighted by the size of its patches (Rempel and Carr, 2003). This variable measures the extent to which patch shapes deviates from circularity, reflecting increases in edge-affected habitats with increasing patch complexity. Landscape metrics were computed using the Patch Analyst extension (version 3.2) of Arc View ${ }^{\circledR}$ GIS (Rempel and Carr, 2003). The densities of linear structures such as roads, irrigation channels and arboreal and shrubby windbreaks (Table 1 ) were also estimated using aerial photography and thorough field surveys.

\subsection{Data analysis}

Prior to statistical analysis, species richness and abundance data were log-transformed to approach normality and to reduce the influence of extreme values. Species occurring in less than 25\% of sampling plots were excluded when modelling densities of individual species, though they were considered when computing carnivore species richness and overall abundances. The angular transformation (arcsine $\sqrt{p}$ ) was used likewise for proportional landscape data, overcoming problems associated with the unity sum constraint, whereas other habitat variables showing skewed distributions were log-transformed (Zar, 1996). A Principal Component Analysis (PCA) of habitat variables was used to investigate multicollinearity and to describe dominant landscape gradients (Legendre and Legendre, 1998). A varimax normalized rotation was applied to the set of principal components with eigenvalues $>1$, to obtain simpler and more interpretable ecological gradients (Legendre and Legendre, 1998).

Carnivore responses to landscape gradients extracted from PCA were estimated with linear mixed-effects models (Pinheiro and Bates, 2000), thereby accounting for the potential lack of independence between sets of plots sampled in different years and among surveys carried out within a plot on different occasions. In the present design, individual plots, sampling season and year were treated as random effects and all other explanatory variables as fixed effects. All mixed models were fitted in R 2.7.2 software ( $R$ Development Core Team, 2008) using the lme function of the NLME package (Pinheiro et al., 2007). Spatial autocorrelation in species distributions was not accounted for in modelling, because a preliminary analysis based on the Moran $(I)$ index did not indicate the presence of a significant spatial structure for any species $(|z|<1.96$; Lee and Wong, 2001). Modelling involved a two-stage procedure, based on the Information Theoretic Approach (ITA) of Burnham and Anderson (2002). The ITA looks for simplicity and parsimony of several working hypothesis and it is based on the strength of evidence of each candidate predictive model. The AIC adjusted for small samples (AICc) was used as a measure of information loss of each candidate model, with the best fitting model having the lowest AICc and the highest Akaike weight $\left(w_{i}\right)$, which measures the posterior probability that a given model is true, given the data and the set of competing candidate models (Burnham and Anderson, 2002). Only fixed effects were screened in model selection, as the random effects were always incorporated to account for potential lack of independence among samples. Accordingly, the null model considered in model selection was that fitted only to the random effects.

Model selection started by evaluating alternative response curves of carnivores to each landscape gradient. Only linear $(X)$ and quadratic $\left(X^{2}\right)$ responses were evaluated, to avoid developing overly complex models given the relatively limited dataset. Because principal components take both positive and negative values, the quadratic term was sufficient to specify unimodal and U-shaped curves. For each principal component and response variable, the best fitting curve was carried forward to subsequent analysis, using Akaike weights $\left(w_{i}\right)$ as the model selection criteria (Burnham and Anderson, 2002). In each case, scatterplots and regression diagnostics were used to inspect the shape of the fitted curves and to check for eventual problems resulting from the presence of outliers and influential points (Legendre and Legendre, 1998). A second set of analyses involved the development of multivariate models describing the relationships between each response variable and the ecological gradients reflected in the components extracted from PCA. In each case, models were selected from all possible combinations of principal components, using ITA (Burnham and Anderson, 2002). Additionally, we used Multimodel Inference (MI) to assess the magnitude of the effects of predictors on the response variables, which is based on an estimated weighted average across all models based on the model weights (Burnham and Anderson, 2002). Unconditional standard errors of estimates were used to evaluate the precision of modelaverage estimates using a 95\% confidence interval. Estimates whose confidence limits included zero were viewed as having equivocal meaning (Burnham and Anderson, 2002).

\section{Results}

\subsection{Landscape patterns}

Sampling plots represented a wide range of variability in farmland landscape composition and configuration (Table 1). The PCA extracted four axes with eigenvalues $>1$, together accounting for $77.4 \%$ of variance in the original data (Table 2 ). The varimax rotation revealed a major gradient (PC1) largely reflecting the fragmentation of arable landscapes associated with increasing human occupation, as indicated by the concurrent increase in the proportional cover by social areas, in edge density and shape 
Table 2

Factor loadings of habitat variables on the four axes with eigenvalues $>1.0$ extracted by a PCA of landscape variables, after a varimax normalized rotation, and the proportion of variance accounted for by each axis. Values in bold indicate factor loadings $>|0.50|$.

\begin{tabular}{lccrr}
\hline Variables & PC1 & PC2 & \multicolumn{1}{c}{ PC3 } & \multicolumn{1}{c}{ PC4 } \\
\hline Agricultural land cover & 0.04 & $\mathbf{0 . 9 0}$ & 0.20 & -0.33 \\
Social areas cover & $\mathbf{0 . 5 7}$ & -0.09 & 0.15 & 0.28 \\
Forest plantations cover & -0.03 & -0.18 & -0.03 & $\mathbf{0 . 9 2}$ \\
Semi-natural habitats cover & -0.16 & $-\mathbf{0 . 9 1}$ & -0.20 & -0.21 \\
MPS & -0.32 & $\mathbf{0 . 7 6}$ & -0.12 & -0.39 \\
ED & $\mathbf{0 . 8 8}$ & 0.14 & 0.34 & 0.03 \\
AWMFD & $\mathbf{0 . 8 4}$ & -0.11 & 0.04 & -0.03 \\
Irrigation channels & -0.004 & 0.18 & $\mathbf{0 . 7 8}$ & -0.20 \\
Roads & $\mathbf{0 . 5 7}$ & -0.02 & -0.14 & 0.43 \\
Tree hedges & 0.11 & 0.05 & $\mathbf{0 . 8 7}$ & 0.14 \\
Shruby hedges & $\mathbf{0 . 8 4}$ & 0.12 & -0.17 & -0.24 \\
\% variance & 28.6 & 25.8 & 13.3 & 9.6 \\
\hline
\end{tabular}

complexity of arable patches, and in the densities of roads and shrubby hedges. Landscape fragmentation was also reflected in a secondary gradient (PC2) describing an increasing size of agricultural patches at the expense of semi-natural habitats. PC2 is therefore a measure of the relative importance of agricultural habitats within the landscape, reflecting landscape simplification by field enlargement, openness and homogenisation. The third gradient (PC3) is related with irrigated agriculture, as reflected by the concurrent increase in the density of irrigation channels and tree line windbreaks. The final gradient extracted (PC4) describes an increasing cover by forest plantations (Table 2 ).

\subsection{Carnivore assemblage patterns}

A total of 2005 identifiable signs from 10 carnivore species were recorded along $399.2 \mathrm{~km}$ of transects surveyed in southwestern Portugal, about half of which (48.5\%) corresponded to footprints (Table 3 ). Pooling the three sampling seasons, the mean number of species recorded per sampling site was $4.0 \pm 0.1$ (S.E.), with $2.7 \pm 0.1$ wild species and $1.4 \pm 0.04$ domestic species per site. Red foxes (V. vulpes), domestic dogs (Canis domesticus) and Egyptian mongooses (Herpestes ichneumon) were the most widespread and abundant carnivores, accounting respectively for $37.9 \%$, $26.1 \%$ and $17.6 \%$ of the signs recorded (Table 3). Eurasian badgers (Meles meles) and domestic cats (Felis catus) were also recorded in over half the sampling sites, but they only represented $6.0 \%$ and $5.5 \%$ of signs recorded, respectively. Eurasian otters (4.0\% of total records) and weasel ( $0.9 \%$ of total records) occurred in just over one-quarter of sampling sites (Table 3 ). The European polecat (Mustela putorius), the stone marten (Martes foina), and the common genet (Geneta geneta) occurred rarely ( $<25 \%$ of sampling plots) (Table 3).

\subsection{Carnivore responses to landscape patterns}

Preliminary screening of alternative response curves provided strong support for landscape composition and configuration influencing the species richness and abundance of carnivores in farmland landscapes of southwestern Portugal, though the type and strength of such relationships varied greatly (Table 4). In general, carnivore responses to landscape gradients tended to be linear, though there was also support for some unimodal response curves, underlining the presence of peaks in species richness or abundance at intermediate values of the landscape gradients identified (Table 4). In a few cases, Akaike weights supported the presence of U-shaped curves, reflecting maximal carnivore abundances at both extremes of a landscape gradient (Table 4). The curves with the strongest support were used in the model selection exercise (Table 4), which indicated that there was a large set of plausible models (i.e. a 95\% confidence set of models) for each response variable (9-15 out of 16 possible models), with relatively low plausability for each of the best ranking models in terms of AICc $\left(0.134 \leq w_{i} \leq 0.364\right)$ (Table 5$)$. Despite the relatively low plausibility of most individual models, some landscape gradients showed high selection probabilities, indicating consistent effects on carnivore species richness and abundances (Table 5).

The cover by semi-natural versus agricultural habitats reflected in PC2 was always included in the best AICc models for species richness, showing comparatively high selection probabilities in all cases (0.71-0.83). The species richness of domestic species declined with increasing cover by large agricultural patches, whereas the total and wild species richness showed a unimodal response to this gradient, peaking in landscapes with intermediate cover by semi-natural and arable habitats (Table 4 ). The best species richness models also included the effects of human occupation (PC1) and irrigation (PC3), but only the positive relationship between human occupation and domestic species richness showed a high selection probability (Table 5). The irrigation gradient reflected in PC3 affected the total and wild species richness, indicating that the number of these species was positively affected by increasing density of irrigation channels and tree line windbreaks (Table 4). However, there was equivocal support for this variable (selection probabilities of 0.65 and 0.66 ) in multimodel inference (Table 5).

The cover by forest plantations reflected in PC4 was the landscape gradient most consistently affecting positively the abundance of carnivores (Table 4), showing comparatively high selection probabilities in cat, fox, badger, and wild and total carnivore abundance models (0.77-0.92) (Table 5). There was a weak tendency for forest plantations affecting negatively the abundance of weasels (Table 4), but support for this variable was equivocal (Table 5). The irrigation gradient (PC3) showed a

Table 3

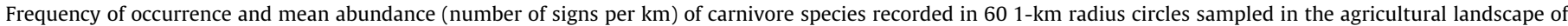
southwestern Portugal, in 2002 and 2003.

\begin{tabular}{|c|c|c|}
\hline Carnivore species & Frequency of occurrence (\%) & Relative abundance (mean \pm S.E.) \\
\hline Dog (Canis familiaris) & 100.0 & $1.4 \pm 0.1$ \\
\hline Cat (Felis catus) & 75.0 & $0.29 \pm 0.03$ \\
\hline Domestic species & 100.0 & $1.6 \pm 0.1$ \\
\hline Red fox (Vulpes vulpes) & 100.0 & $2.0 \pm 0.1$ \\
\hline Eurasian badger (Meles meles) & 56.7 & $0.31 \pm 0.04$ \\
\hline Eurasian otter (Lutra lutra) & 30.0 & $0.21 \pm 0.05$ \\
\hline Weasel (Mustela nivalis) & 26.7 & $0.04 \pm 0.01$ \\
\hline European polecat (Mustela putoris) & 18.3 & $0.04 \pm 0.01$ \\
\hline Stone Marten (Martes foina) & 16.7 & $0.04 \pm 0.01$ \\
\hline Egyptian mongoose (Herpestes ichneumon) & 95.0 & $0.90 \pm 0.06$ \\
\hline Genet (Genetta genetta) & 16.7 & $0.03 \pm 0.01$ \\
\hline Wild species & 100.0 & $3.5 \pm 0.2$ \\
\hline
\end{tabular}


Table 4

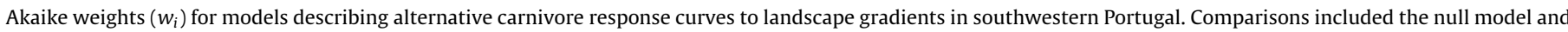

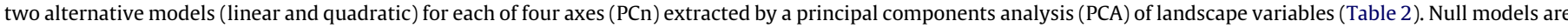

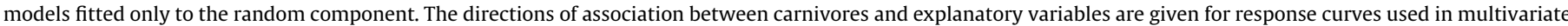
analysis: $(+)$ positive, $(-)$ negative, $(\cap)$ unimodal, and $(\cup) U$-shaped.

\begin{tabular}{|c|c|c|c|c|c|c|c|c|c|c|c|c|}
\hline \multirow[t]{2}{*}{ Carnivores } & \multicolumn{3}{|l|}{ PC1 } & \multicolumn{3}{|l|}{ PC2 } & \multicolumn{3}{|l|}{ PC3 } & \multicolumn{3}{|l|}{ PC4 } \\
\hline & Null & Linear & Quadratic & Null & Linear & Quadratic & Null & Linear & Quadratic & Null & Linear & Quadratic \\
\hline \multicolumn{13}{|l|}{ Species richness } \\
\hline Domestic species & 0.16 & $0.77(+)$ & 0.07 & 0.26 & $0.64(-)$ & 0.10 & 0.55 & 0.20 & $0.25(\cup)$ & 0.57 & $0.22(+)$ & 0.21 \\
\hline Wild species & 0.47 & $0.30(-)$ & 0.22 & 0.17 & 0.06 & $0.77(\cap)$ & 0.23 & $0.63(+)$ & 0.14 & 0.46 & $0.31(+)$ & 0.23 \\
\hline Overall & 0.53 & 0.19 & $0.28(\cap)$ & 0.19 & 0.11 & $0.70(\cap)$ & 0.24 & $0.58(+)$ & 0.18 & 0.45 & $0.32(+)$ & 0.23 \\
\hline \multicolumn{13}{|l|}{ Abundances } \\
\hline Dog & 0.36 & $0.49(+)$ & 0.15 & 0.53 & $0.24(-)$ & 0.23 & 0.39 & $0.44(+)$ & 0.17 & 0.54 & $0.25(+)$ & 0.21 \\
\hline Cat & 0.31 & $0.56(+)$ & 0.13 & 0.34 & $0.53(-)$ & 0.14 & 0.51 & $0.30(+)$ & 0.19 & 0.12 & $0.64(+)$ & 0.24 \\
\hline Domestic species & 0.27 & $0.63(+)$ & 0.10 & 0.49 & $0.31(-)$ & 0.20 & 0.37 & $0.48(+)$ & 0.15 & 0.46 & $0.37(+)$ & 0.17 \\
\hline Fox & 0.52 & 0.23 & $0.25(\cap)$ & 0.46 & $0.28(-)$ & 0.26 & 0.51 & 0.20 & $0.29(\cup)$ & 0.20 & $0.71(+)$ & 0.08 \\
\hline Mongoose & 0.42 & $0.42(+)$ & 0.16 & 0.37 & 0.15 & $0.48(\cap)$ & 0.21 & 0.08 & $0.72(\cup)$ & 0.51 & $0.31(+)$ & 0.19 \\
\hline Badger & 0.56 & 0.22 & $0.23(\cap)$ & 0.20 & 0.08 & $0.71(\cap)$ & 0.51 & 0.20 & $0.29(\cup)$ & 0.05 & $0.92(+)$ & 0.03 \\
\hline Otter & 0.32 & $0.52(-)$ & 0.16 & 0.32 & $0.52(+)$ & 0.16 & 0.07 & $0.90(+)$ & 0.03 & 0.49 & 0.21 & $0.30(\cap)$ \\
\hline Weasel & 0.55 & 0.22 & $0.23(\cup)$ & 0.30 & $0.53(-)$ & 0.17 & 0.50 & 0.19 & $0.30(\cup)$ & 0.32 & $0.56(-)$ & 0.12 \\
\hline Wild species & 0.55 & $0.22(+)$ & 0.22 & 0.43 & 0.17 & $0.41(\cap)$ & 0.32 & 0.15 & $0.53(\cup)$ & 0.23 & $0.68(+)$ & 0.09 \\
\hline Overall & 0.48 & $0.31(+)$ & 0.21 & 0.49 & 0.19 & $0.33(\cap)$ & 0.34 & 0.24 & $0.42(\cup)$ & 0.28 & $0.62(+)$ & 0.11 \\
\hline
\end{tabular}

consistent positive effect on the abundance of otters, whereas the total abundance of wild carnivores and that of mongooses showed a U-shaped response to this gradient. The later effect suggests an increased abundance of mongooses and wild carnivores in landscapes with the highest densities of irrigation channels and tree line windbreaks, as well as in landscapes where irrigated agriculture was largely absent. The remaining two landscape gradients showed less consistent effects on carnivore abundances (Table 5). The gradient of increasing human occupation and arable land fragmentation represented in PC1 showed a positive effect on the overall abundance of domestic carnivores and on that of cats, and a negative effect on otters (Table 4). The gradient of increasing cover by large agricultural patches at the expenses of semi-natural habitats, reflected in $\mathrm{PC} 2$, was positively associated with the abundance of otters and negatively so with the abundance of cats and weasel, whereas badgers showed a unimodal response to this gradient (Table 4 ).

\section{Discussion}

In farmland landscapes of southwestern Portugal there was a diverse carnivore assemblage, including most medium-sized species occurring in Mediterranean forest and shrubland habitats of the southwestern Iberian Peninsula (e.g., Grilo et al., 2008; Santos et al., 2008; Matos et al., 2009; Beja et al., in press). Only wild cats (Felis sylvestris) were represented in the regional species pool but were not recorded in the famed landscape, probably due to their association with more forested and less disturbed habitats (Virgós et al., 2002; Lozano et al., 2003). Despite its diversity, the carnivore assemblages were largely dominated by just three widespread and abundant generalist predators, including one domestic species (dog), one native species (red fox), and one exotic species (Egyptian mongoose), with most of the remaining species showing restricted distributions and low abundance. These results confirm the view that farmland habitats can be favourable environments for generalist mammalian predators, which can profit from the abundance of food resources available in humandominated landscapes and thus reach higher densities than in more natural habitats (e.g., Evans, 2004; Sobrino et al., in press).

\subsection{Carnivore responses to landscape patterns}

In common with other studies (Gehring and Swihart, 2003; Matos et al., 2009), the amount and configuration of non-

Table 5

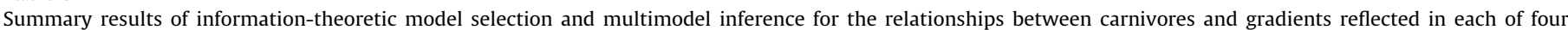

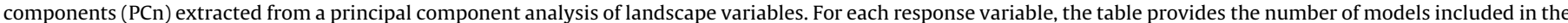

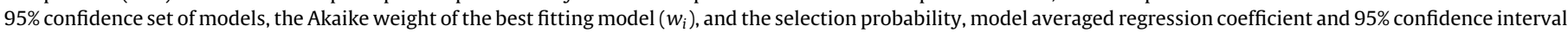
of each principal component (PCn). Selection probabilities of PC included in the best fitting model are underlined.

\begin{tabular}{|c|c|c|c|c|c|c|c|c|c|c|}
\hline \multirow[t]{2}{*}{ Carnivores } & \multirow[t]{2}{*}{ 95\% models } & \multirow[t]{2}{*}{$w_{i}$} & \multicolumn{4}{|c|}{ Selection probabilities } & \multicolumn{4}{|c|}{ Model averaged coefficients ( $b i[95 \% \mathrm{CI}]$ ) } \\
\hline & & & PC1 & PC2 & PC3 & PC4 & PC1 & PC2 & PC3 & PC4 \\
\hline \multicolumn{11}{|l|}{ Species richness } \\
\hline Domestic species & 12 & 0.305 & $\underline{0.81}$ & $\underline{0.75}$ & 0.33 & 0.26 & $0.02(0.001,0.04)$ & $-0.02(-0.04,-0.001)$ & $0.01(-0.01,0.03)$ & $0.003(-0.01,0.02)$ \\
\hline Wild species & 12 & 0.253 & $\underline{0.60}$ & $\overline{0.83}$ & 0.66 & 0.28 & $-0.02(-0.05,0.01)$ & $-0.03(-0.05,-0.004)$ & $0.02(-0.001,0.04)$ & $0.01(-0.021,0.03)$ \\
\hline Overall & 14 & 0.216 & $\overline{0.34}$ & $\overline{0.71}$ & $\overline{0.65}$ & 0.31 & $-0.01(-0.02,0.01)$ & $-0.02(-0.03,-0.0003)$ & $0.02(-0.001,0.04)$ & $0.01(-0.013,0.03)$ \\
\hline \multicolumn{11}{|l|}{ Abundances } \\
\hline Dog & 14 & 0.160 & 0.53 & 0.33 & 0.56 & 0.32 & $0.18(-0.05,0.41)$ & $-0.07(-0.29,0.15)$ & $0.17(-0.05,0.38)$ & $0.08(-0.14,0.30)$ \\
\hline Cat & 12 & 0.257 & $\overline{0.66}$ & $\underline{0.67}$ & $\overline{0.36}$ & $\underline{0.87}$ & $0.06(-0.02,0.14)$ & $-0.06(-0.12,0.001)$ & $0.03(-0.03,0.09)$ & $0.08(0.02,0.14)$ \\
\hline Domestic species & 15 & 0.134 & $\underline{0.70}$ & $\overline{0.38}$ & $\underline{0.56}$ & $\overline{0.44}$ & $0.24(-0.02,0.50)$ & $-0.13(-0.37,0.10)$ & $0.20(-0.04,0.43)$ & $0.17(-0.08,0.41)$ \\
\hline Fox & 12 & 0.157 & $\overline{0.36}$ & $\underline{0.44}$ & $\overline{0.59}$ & $\underline{0.82}$ & $-0.12(-0.38,0.14)$ & $-0.21(-0.51,0.10)$ & $0.24(-0.08,0.56)$ & $0.37(0.07,0.67)$ \\
\hline Mongoose & 13 & 0.162 & 0.37 & $\overline{0.46}$ & $\overline{0.79}$ & $\overline{0.42}$ & $0.08(-0.08,0.24)$ & $-0.09(-0.22,0.04)$ & $0.17(0.02,0.32)$ & $0.10(-0.06,0.26)$ \\
\hline Badger & 10 & 0.216 & 0.34 & 0.43 & $\underline{0.57}$ & 0.92 & $-0.03(-0.12,0.05)$ & $-0.06(-0.15,0.03)$ & $0.08(-0.03,0.18)$ & $0.15(0.04,0.26)$ \\
\hline Otter & 9 & 0.309 & $\underline{0.65}$ & $\underline{0.66}$ & $\overline{0.94}$ & $\overline{0.26}$ & $-0.12(-0.28,0.03)$ & $0.13(-0.003,0.26)$ & $0.19(0.06,0.32)$ & $-0.01(-0.11,0.08)$ \\
\hline Weasel & 14 & 0.157 & $\overline{0.31}$ & $\overline{0.57}$ & $\overline{0.39}$ & $\underline{0.66}$ & $0.01(-0.01,0.02)$ & $-0.02(-0.04,0.003)$ & $-0.01(-0.03,0.01)$ & $-0.02(-0.04,0.001)$ \\
\hline Wild species & 12 & 0.364 & 0.26 & 0.32 & 0.78 & $\overline{0.83}$ & $0.001(-0.49,0.50)$ & $-0.16(-0.60,0.29)$ & $0.54(0.05,1.01)$ & $0.59(0.10,1.09)$ \\
\hline Overall & 13 & 0.285 & 0.33 & 0.29 & $\overline{0.68}$ & $\overline{0.77}$ & $0.27(-0.38,0.91)$ & $-0.13(-0.70,0.43)$ & $0.60(-0.01,1.21)$ & $0.72(0.09,1.35)$ \\
\hline
\end{tabular}


agricultural habitats appeared to be important factors influencing carnivore diversity and abundances in farmland landscapes of southwestern Portugal. In general, the richest carnivore assemblages and the highest abundances were attained in mosaic landscapes, where forests and shrubland were interspersed in otherwise open arable land.

As it might be expected, more domestic carnivores were found in landscapes with greater occupation by small villages, farms and rural housing. This was particularly evident in the case of cats, probably because they tend to centre their activity on human settlements, which are sources of food and resting sites (Barratt, 1997; Biró et al., 2003; Germain et al., 2008). However, the abundance of cats also increased with the area covered by forest plantations, though reasons for this are unclear. One possibility is that feral cats not associated with any human settlement were living in woodlots within the farmed landscape, but this could not be confirmed from data collected in this study. The abundance of dogs was not related to any landscape variable, probably because they occurred more evenly across farmland in association with a range of human activities such as cattle herding and hunting.

Contrary to domestic species, the diversity of wild carnivores was largely unrelated to the prevalence of human settlements, being primarily influenced by the relative proportion of seminatural versus arable habitats in the farmed landscape. Few carnivore species were recorded in landscapes dominated by large arable patches and little cover by semi-natural habitats such as cork oak woodlands and Mediterranean forest and shrubland patches, whereas species richness peaked in landscapes with a patchwork of arable and semi-natural patches. Below a threshold of arable land cover the number of carnivore species declined again, suggesting that it was the presence of a mosaic landscape of open and woody habitat patches that favoured carnivore diversity, and not only the prevalence of semi-natural habitats. This result agrees with previous findings showing that several medium-sized Iberian carnivores are positively influenced by the presence of mosaic landscapes, which probably provide a favourable combination of secure shelter in woody habitats and food resources at habitat edges and in adjacent open land (Revilla et al., 2000; Lozano et al., 2003; Mestre et al., 2007; Mangas et al., 2008; Matos et al., 2009). For instance, although rabbits are scarce throughout the study area, they tend to occur most frequently at the edge of shrubland habitats (Beja et al., 2007), which may thus provide favourable foraging grounds for a range of carnivores that feed preferentially on this prey (Delibes-Mateos et al., 2007).

Forest plantations also appeared to strongly influence carnivore assemblages in Mediterranean farmland, positively affecting cat, fox, badger, and total and wild carnivore abundances. This result is in line with previous research pointing out the importance of forest fragments for carnivore conservation in otherwise open landscapes of the Iberian Peninsula (Virgós, 2001; Virgós et al., 2002). More generally, this result agrees with the idea that woodlots within agricultural mosaics may act as safe harbourages offering alternative food and breeding resources that may be scarce in the wider landscape, thereby promoting species abundance and spread (Gehring and Swihart, 2003; Baker and Harris, 2006). It is noteworthy that this effect was evident even though forest patches in the study area were plantations dominated by exotic tree species such as eucalyptus. These forest stands probably provide secure shelter to carnivores because they are little disturbed by human activities for long periods of time, in landscapes otherwise subject to periodic agricultural operations.

The influential role of woody habitats on carnivore diversity and abundance was likely to be at least partly responsible for the observed responses to the landscape gradient associated with irrigated agriculture. In fact, irrigated fields were often bordered by tree lines planted to protect crops from saline winds, which caused a joint variation in the densities of tree lines and irrigation channels. Tree lines may be favourable carnivore refuges and travelling corridors (Gehring and Swihart, 2003), thereby justifying the increased species richness and overall abundance of wild carnivores, and in the abundance of mongooses, in the most irrigated landscapes. It should be noted, however, that the relationships between this landscape gradient and wild carnivore and mongoose abundances was U-shaped, suggesting that there were peak abundances in both the most irrigated landscapes and in landscapes where tree lines and irrigation channels were largely absent. The latter likely represent landscapes dominated by less-intensive agriculture, where the positive effect of tree line windbreaks may be replaced by a more diverse array of woody structures. The positive responses of mongooses to irrigated landscapes may also result from their association with small streams and areas with a higher ground water table (Palomares and Delibes, 1993; Matos et al., 2009). The availability of water in irrigation channels was another likely factor eliciting carnivore responses to the irrigated agriculture landscape gradient. This was particularly obvious in the case of otters, which showed peak abundances in the most irrigated landscapes. Otters are regionally abundant in both coastal and inland habitats (Beja, 1996a), probably finding in irrigation channels adequate food resources such as fish, the crayfish Procambarus clarkii, and amphibians (Beja, 1996b). These resources may also be found in irrigation ponds that often occur in irrigated land, though these permanent ponds often replace important amphibian breeding habitats such as temporary ponds (Beja and Alcazar, 2003). Amphibians and crayfish available in irrigation channels and ponds may also be important food resources for other carnivores (Correia, 2001; Zapata and Travaini, 2007), which may contribute to their positive responses to irrigated landscapes.

\subsection{Conservation implications}

The presence of abundant woody cover seemed to be the critical factor promoting carnivore diversity and abundance in Mediterranean farmland, supporting the view that the maintenance of shrubland patches, hedges, woodlots and riparian galleries is a key option where the conservation of carnivores within farmed landscapes is a relevant management goal (Gehring and Swihart, 2003; Matos et al., 2009). However, most carnivores recorded in the study area were widespread generalists of least conservation concern, adding to the growing evidence that carnivore assemblages inhabiting Mediterranean farmland may generally represent reduced subsets of the species pool occurring in adjacent forest and shrubland habitats (Revilla et al., 2000; Virgós, 2001; Virgós et al., 2002; Mangas et al., 2008; Matos et al., 2009). None of the wild carnivores recorded in this study is considered of conservation concern in Portugal (Cabral et al., 2005), though the otter is a species of community interest listed in Annex II of the Council Directive 92/43/EEC. It is unlikely, however, that irrigation channels and ponds in farmland landscapes provide a particularly relevant habitat for this species, which is abundant in streams, rivers and coastal areas throughout the region (e.g., Beja, 1996a). Farmland habitats may be more important for the polecat, which has an uncertain conservation status in Portugal (Cabral et al., 2005). In Mediterranean farmland this species tends to be associated with riparian corridors and shrubland patches (Mestre et al., 2007), but this could not be assessed in the present study because polecats were recorded infrequently in carnivore surveys. Although it is unknown whether the current trends of agricultural intensification will negatively affect polecats, there is some evidence that irrigated agriculture may be compatible with the occurrence of this species, provided some woody cover is retained within the farmed landscape (Mestre et al., 2007). The wild cat is another carnivore of conservation concern that may occur in 
Mediterranean agricultural landscapes (Lozano et al., 2003; Sobrino et al., in press), though it is generally associated with rather stringent ecological conditions such as low human occupation, high prey abundance (mainly rabbits) and high cover by forests and shrubland (Virgós et al., 2002; Lozano et al., 2003). This probably justifies why the species was not recorded in this and other studies carried out in lowland farmland landscapes of the southern Iberian Peninsula (Matos et al., 2009), where adequate habitat conditions may rarely be met. Altogether, these results suggest that carnivore conservation in Mediterranean farmland landscapes should only be ascribed a high priority where they are important for species of conservation concern such as the wild cat (e.g., Lozano et al., 2003), given the low conservation status of most of the species involved and their potential negative interactions with other species of much higher conservation concern.

The prevalence of generalist predators recorded by this study in Mediterranean farmland landscapes may be of conservation concern, due to the potential predatory pressure on declining populations of some farmland species, particularly ground-nesting birds of high conservation concern (Suárez et al., 1993; Yanes and Suárez, 1996). These putative negative effects may be particularly serious in farmland fields close to houses, where the highest cat abundances were recorded. Cats can reach high densities independently of prey abundance because humans feed them, and so their subsidised populations may represent a significant source of mortality for passerines and small mammals (Baker et al., 2003, 2008; Sims et al., 2008). Subsidised predation by dogs may be even more serious (Suárez et al., 1993; Yanes and Suárez, 1996), as these domestic predators were more abundant than cats and their activity was spread across the farmed landscape and not restricted to areas near houses. Predation pressure by wild carnivores was likely higher in farmland landscapes with small arable fields and high cover by woody patches and corridors. These landscapes appeared to favour the abundance of generalist carnivores such as foxes and mongooses, which are known to reduce populations of their prey in at least some circumstances (Suárez et al., 1993; Palomares et al., 1996; Yanes and Suárez, 1996). This may help explaining why at least some open farmland birds show a strong avoidance to woody edges (Reino et al., 2009) and occur at reduced density in landscapes fragmented by woody habitats (Moreira et al., 2005).

In general, this study suggests that predation pressure by mammalian carnivores in Mediterranean farmland is probably lowest in areas with continuous expanses of large arable fields, few houses and reduced cover by woody vegetation, as these conditions tend to determine reduced abundances of both domestic and wild generalist carnivores. Low predation pressure may thus be one of the factors favouring the occurrence in open farmland landscapes of a range of ground-nesting birds of conservation concern, including species threatened at the global or European levels such as the great bustard (Otis tarda) and the little bustard (Tetrax tetrax) (Brotons et al., 2004; Silva et al., 2004; Moreira et al., 2005). In these circumstances, the need to maintain low populations of generalist carnivores should be incorporated in agri-environmental management prescriptions for open farmland landscapes, namely by preventing the development of woody vegetation patches and corridors. This further emphasises the need to revert current trends for scrub encroachment and afforestation of marginal agricultural land in the Mediterranean region, as this process may have the dual negative impact of reducing valuable farmland habitats, while likely adding predation pressure to remnant farmland fields (Shapira et al., 2008).

\section{Acknowledgements}

This study was funded by Portuguese Foundation for Science and Technology (project POCTI/BSE/38601/2001: “Agricultural changes and avian nest predation in Mediterranean arable farmland: the role of habitat edges and corridors"). Thanks are due to Susana Rosa and Pedro Mendes for comments and suggestions regarding the data analyses, and two anonymous referees for helpful comments and suggestions to improve the paper.

\section{References}

Alcazar, R., 2003. Biodiversidade e intensificação agrícola: modelação ecológica e orientações para um planeamento ambiental. MSc Thesis. New University of Lisbon.

Aranzabal, I., Schmitz, M.F., Aquilera, P., Pineda, F.D., 2008. Modelling of landscape changes derived from the dynamics of socio-ecological systems-a case of study in a semiarid Mediterranean landscape. Ecol. Indic. 8, 672-685.

Aschwanden, J., Holzgang, O., Jenni, L., 2007. Importance of ecological compensation areas for small mammals in intensively farmed areas. Wildlife Biol. 13, 150158.

Baker, P.J., Ansell, R.J., Dodds, P.A.A., Webber, C.E., Harris, S., 2003. Factors affecting the distribution of small mammals in an urban area. Mammal Rev. 33, 95-100.

Baker, P.J., Harris, S., 2006. Does culling reduce fox (Vulpes vulpes) density in commercial forests in Wales, UK? Eur. J. Wildlife Res. 52, 99-108.

Baker, P.J., Molony, S.E., Stone, E., Cuthill, I.C., Harris, S., 2008. Cats about town: is predation by free-ranging pet cats Felis catus likely to affect urban bird populations? Ibis 150, 86-99.

Barea-Azcón, J.M., Virgós, E., Ballesteros-Duperón, E., Moleón, M., Chirosa, M., 2006. Surveying carnivores at large spatial scales: a comparison of four broad-applied methods. Biodivers. Conserv. 16, 1213-1230.

Barratt, D.G., 1997. Home range size, habitat utilisation and movements patterns of suburban and farm cats Felis catus. Ecography 20, 271-280.

Beja, P., 1996a. Seasonal breeding and food resources of otters Lutra lutra in southwest Portugal: a comparison between coastal and inland habitats. Mammalia 60, 27-34.

Beja, P., 1996b. An analysis of otter Lutra lutra predation on introduced American crayfish Procambarus clarkii in Iberian streams. J. Appl. Ecol. 33, 1156-1170.

Beja, P., Alcazar, R., 2003. Conservation of Mediterranean temporary ponds under agricultural intensification: an evaluation using amphibians. Biol. Conserv. 114, 317-326.

Beja, P., Gordinho, L., Reino, L., Loureiro, F., Santos-Reis, M., Borralho, R., in press. Predator abundance in relation to small game management in southern Portugal: conservation implications. Eur. J. Wildlife Res. doi:10.1007/s10344-0080236-1.

Beja, P., Pais, M., Palma, L., 2007. Rabbit Oryctolagus cuniculus habitats in Mediterranean Scrubland: the role of scrub structure and composition. Wildlife Biol. $13,28-37$.

Benton, T.G., Vickery, J.A., Wilson, J.D., 2003. Farmland biodiversity: is habitat heterogeneity the key? Trends Ecol. Evol. 18, 182-188.

Biró, Z., Szemethy, L., Heltai, M., 2003. Home range sizes of wildcats (Felis silvestris) and feral domestic cats (Felis silvestris f. catus) in a hilly region of Hungary. Mammal. Biol. 69, 302-310.

Brotons, L., Mañosa, S., Estrada, J., 2004. Modelling the effects of irrigation schemes on the distribution of steppe birds in Mediterranean farmland. Biodivers. Conserv. 13, 1039-1058.

Burnham, K.P., Anderson, D.R., 2002. Model Selection and Multimodel Inference: A Practical Information-theoretic Approach. Springer, New York.

Cabral, M.J., Almeida, J., Almeida, P.R., Dellinger, T., Ferrand de Almeida, N., Oliveira M.E., Palmeirim, J.M., Queiroz, A.I., Rogado, L., Santos-Reis, M., 2005. Livro Vermelho dos Vertebrados de Portugal. Instituto da Conservação da Natureza, Lisboa.

Calvete, C., Estrada, R., Angulo, E., Cabezas-Ruiz, S., 2004. Habitat factors related to wild rabbit conservation in an agricultural landscape. Landscape Ecol. 19, $531-$ 542.

Correia, A.M., 2001. Seasonal and interspecific evaluation of predation by mammals and birds on the introduced red swamp crayfish Procambarus clarkii (Crustacea, Cambaridae) in a freshwater marsh (Portugal). J. Zool. (Lond.) 255, 533-541.

Delibes-Mateos, M., Redpath, S.M., Angulo, E., Ferreras, P., Villafuerte, R., 2007. Rabbits as a keystone species in southern Europe. Biol. Conserv. 137, 149-156.

Eggers, S., Griesser, M., Andersson, T., Ekman, J., 2005. Nest predation and habitat change interact to influence Siberian jay numbers. Oikos 111, 150-158.

Evans, K.L., 2004. The potential for interactions between predation and habitat change to cause population declines of farmland birds. Ibis 146, 1-13.

Falcucci, F., Maiorano, L., Boitani, L., 2007. Changes in land-use/land-cover patterns in Italy and their implications for biodiversity conservation. Landscape Ecol. 22, 617-631.

Gehring, T.M., Swihart, R.K., 2003. Body size, niche breadth, and ecologically scaled responses to habitat fragmentation: mammalian predators in an agricultural landscape. Biol. Conserv. 109, 283-295.

Germain, E., Benhamou, S., Poulle, M.-L., 2008. Spatio-temporal sharing between the European wildcat, the domestic cat and their hybrids. J. Zool. (Lond.) 276, 195 203.

Grilo, C., Bissonette, J.A., Santos-Reis, M., 2008. Response of carnivores to existing highway culverts and underpasses: implications for road planning and mitigation. Biodivers. Conserv. 17, 1685-1699.

Henle, K., Alard, D., Clitherow, J., Cobb, P., Firbank, L., Kull, T., McCracken, D., Moritz, R.F.A., Niemela, J., Rebane, M., Wascher, D., Watt, A., Youn, J., 2008. Identifying 
and managing the conflicts between agriculture and biodiversity conservation in Europe-a review. Agric. Ecosyst. Environ. 124, 60-71.

Jongman, R.H.G., 2002. Homogenisation and fragmentation of the European landsacape: ecological consequences and solutions. Landscape Urban Plan 58, 211 221.

Legendre, P., Legendre, L., 1998. Numerical Ecology, 2nd ed. Elsevier, Amsterdam. Lee, J., Wong, D.W.S., 2001. Statistical Analysis with ArcView GIS ${ }^{\mathbb{R}}$. John Wiley \& Sons, Inc., New York.

Lozano, J., Virgós, E., Malo, A.F., Huertas, D.L., Casanovas, J.G., 2003. Importance of scrub-pastureland mosaics for wild living cats occurrence in a Mediterranean area: implications for the conservation of the wildcat (Felis silvestris). Biodivers. Conserv. 12, 921-935.

Maes, J., Musters, C.J.M., Geert, R., De Snoo, G.R., 2008. The effect of agri-environment schemes on amphibian diversity and abundance. Biol. Conserv. 141, 635 645.

Mangas, K.G., Lozano, J., Cabezas-Díaz, S., Virgós, E., 2008. The priority value of scrubland habitats for carnivore conservation in Mediterranean ecosystems. Biodivers. Conserv. 17, 43-51.

Matos, H.M., Santos, M.J., Palomares, F., Santos-Reis, M., 2009. Does riparian habitat condition influence mammalian carnivore abundance in Mediterranean ecosystems? Biodivers. Conserv. 18, 373-386.

Mestre, F.M., Ferreira, J.P., Mira, A., 2007. Modelling the distribution of the European polecat Mustela putorius in a Mediterranean agricultural landscape. Revue d'Écologie (Terre Vie) 62, 35-47.

Moreira, F., Beja, P., Morgado, R., Reino, L., Gordinho, L., Delgado, A., Borralho, R., 2005. Effects of field management and landscape context on grassland wintering birds in Southern Portugal. Agric. Ecosyst. Environ. 109, 59-74.

Palomares, F., Delibes, M., 1993. Key habitats for Egyptian mongooses in Donana National Park, South-Western Spain. J. Appl. Ecol. 30, 752-758.

Palomares, F., Gaona, P., Ferreras, P., Delibes, M., 1996. Positive effects on game species of top predators by controlling smaller predator populations: an example with lynx, mongooses, and rabbits. Conserv. Biol. 9, 295-305.

Pescador, M., Peris, S., 2001. Effects of land use on nest predation: an experimental study in Spanish croplands. Folia Zool. 50, 127-136.

Pinheiro, J.C., Bates, D.M., 2000. Mixed-efffects Models in S and S-Plus. Springer, New York.

Pinheiro, J.C., Bates, D.M., DebRoy, S., Sarkar, D., 2007. NLME: Linear and Nonlinear Mixed Effects Models. R Package Version 3.1-83. URL: http://www. R-project.org.

Pita, R., Beja, P., Mira, A., 2007. Spatial population structure of the Cabrera vole in Mediterranean farmland: the relative role of patch and matrix effects. Biol. Conserv. 134, 383-392.

R Development Core Team, 2008. R: A Language and Environment for Statistica Computing. R Foundation for Statistical Computing, Vienna, Austria. URL: http://www.R-project.org.

Rands, L., Yunger, J.A., 2006. Carnivore occurrence along an urban-rural gradient: a landscape-level analysis. J. Mammal. 87, 1154-1164.

Reino, L., Beja, P., Osborne, P.E., Morgado, R., Fabião, A., Rotenberry, J.T., 2009 Distance to edges, edge contrast and landscape fragmentation: interactions affecting farmland birds around forest plantations. Biol. Conserv. 142, 824-838.

Rempel, R.S., Carr, A.P., 2003. Patch Analyst extension for ArcView: version 3. URL: http://flash.lakeheadu.ca/ rrempel/patch/index.html.

Revilla, E., Palomares, F., Delibes, M., 2000. Defining key habitats for low density populations of Eurasian badgers in Mediterranean environments. Biol. Conserv. 95, 269-277.

Rivas-Martinez, S., 1981. The vegetation of bioclimatic stages of Iberian Peninsula An. Jard. Bot. Madrid 37, 251-268.

Sadlier, L.M.J., Webbon, C.C., Baker, P.J., Harris, S., 2004. Methods of monitoring red foxes Vulpes vulpes and badger Meles meles: are field signs the answer? Mammal Rev. 34, 75-98.
Santos, M.J., Pedroso, N.M., Ferreira, J.P., Matos, H.M., Sales-Luís, T., Pereira, I. Baltazar, C., Grilo, C., Cândido, A.T., Sousa, I., Santos-Reis, M., 2008. Assessing dam implementation impact on threatened carnivores: the case of Alqueva in SE Portugal. Environ. Monit. Assess. 142, 47-64.

Shapira, I., Sultan, H., Shanas, U., 2008. Agricultural farming alters predator-prey interactions in nearby natural habitats. Anim. Conserv. 11, 1-8.

Silva, J.P., Pinto, M., Palmeirim, J.P., 2004. Managing landscapes for the little bustard Tetrax tetrax: lessons from the study of winter habitat selection. Biol. Conserv. $117,521-528$.

Sims, V., Evans, K.L., Newson, S.E., Tratalos, J.A., Gaston, K.J., 2008. Avian assemblage structure and domestic cat densities in urban environments. Divers. Distrib. 14, 387-399.

Sobrino, R., Acevedo, P., Escudero, M.A., Marco, J., Gortázar, C., in press. Carnivore population trends in Spanish agrosystems after the reduction in food availability due to rabbit decline by rabbit haemorrhagic disease and improved waste management. Eur. J. Wildlife Res. doi:10.1007/s10344-008-0230-7.

Stoate, C., Boatman, N.D., Borralho, R.J., Rio Carvalho, C., de Snoo, G.R., Eden, P., 2001. Ecological impacts of arable intensification in Europe. J. Environ. Manage. 63 337-365.

Suárez, F., Vanes, M., Herranz, J., Manrique, J., 1993. Nature reserves and the conservation of Iberian shrubsteppe passerines: the paradox of nest predation. Biol. Conserv. 63, 77-81.

Tuyttens, F.A.M., Long, B., Fawcett, T., Skinner, A., Brown, J.A., Cheeseman, C.L., Roddam, A.W., MacDonald, D.W., 2001. Estimating group size and population density of Eurasian Badgers Meles meles by quantifying latrine use. J. Appl. Ecol. $38,1114-1121$.

Van Doorn, A.M., Bakker, M.M., 2007. The destination of arable land in a marginal agricultural landscape in South Portugal: an exploration of land use change determinants. Landscape Ecol. 22, 1073-1087.

Virgós, E., 2001. Relative value of riparian woodlands in landscapes with different forest cover for medium-sized Iberian carnivores. Biodivers. Conserv. 10, 10391049.

Virgós, E., Telleria, J.L., Santos, T., 2002. A comparison on the response to forest fragmentation by medium-sized Iberian carnivores in central Spain. Biodivers. Conserv. 11, 1063-1079.

Virgós, E., Travaini, A., 2005. Relationship between small-game hunting and carnivore diversity in central Spain. Biodivers. Conserv. 14, 3475-3486.

Vos, W., Meekes, H., 1999. Trends in European cultural landscape development: perspectives for a sustainable future. Landscape Urban Plan 46, 3-14.

Wade, M.R., Gurr, G.M., Wratten, S.D., 2008. Ecological restoration of farmland: progress and prospects. Philos. Trans. Roy. Soc. Lond. B 363 (1492), 831-847.

Walker, R.S., Pancotto, V., Schachter-Broide, J., Ackermann, G., Novaro, A.J., 2000. Evaluation of a fecal-pellet index of abundance for Mountain vizcachas (Lagidium viscacia) in Patagonia. Mastozoología Neotropical/J. Neotrop. Mammal. 7, 89-94.

Wallander, J., Isaksson, D., Lenberg, T., 2006. Wader nest distribution and predation in relation to man-made structures on coastal pastures. Biol. Conserv. 132, 343350

Wilson, G.J., Delahay, R.J., 2001. A review of methods to estimate the abundance of terrestrial carnivores using field signs and observation. Wildlife Res. 28, 151164.

Whittingham, M.J., Evans, K.L., 2004. The effects of habitat structure on predation risk of birds in agricultural landscapes. Ibis 146, 210-220.

Yanes, M., Suárez, 1995. Nest predation patterns in ground-nesting passerines on the Iberian Peninsula. Ecography 18, 423-428.

Yanes, M., Suárez, 1996. Incidental nest predation and lark conservation in an Iberian semiarid shrubsteppe. Conserv. Biol. 10, 881-887.

Zapata, S.C., Travaini, A., 2007. Analysis of trophic structure of two carnivore assemblages by means of guild identification. Eur. J. Wildlife Res. 53, 276-286.

Zar, J.H., 1996. Biostatistical Analysis, 3rd ed. Prentice Hall, New Jersey. 